${ }^{16}$ Rothermich NO. An extended study of indomethacin. $\mathcal{F} A M A 1966 ; 195$, 531-6.

17 Kammerer WH, Frieberger RH, Rivelis AL. Peptic ulcer in rheumatoid patients on corticosteroid therapy: clinical, experimental and radiologic study. Arthritis Rheum 1958;1:122-8.

18 Gedda PO, Moritz U. Peptic ulcer during treatment of rheumatoid arthritis with cortisone derivatives: relationship between duration of therapy and frequency of ulcers. Acta Rheum Scand 1959;4:249-56.

19 Vane JR. The role of prostaglandins in inflammation. In: Lewis GP, ed. Antiinflammatory drugs and inhibition of prostaglandin synthetase. Berne: Stuttgart, Vienna: Hans Huber, 1976:88-107.
${ }^{20}$ Watkinson G. The incidence of chronic peptic ulcer found at necropsy: a study of 20000 examinations performed in Leeds in 1930-49 and in England and Scotland in 1956. Gut 1956;1:14-30.

${ }^{21}$ Conn HO, Blitzer BL. Nonassociation of adrenocorticosteroid therapy and peptic ulcer. New Engl F Med 1976;294:473-9.

22 Caruso I, Fumagalli M, Montrone F, Vernazza M, Bianchi Porro G Petrillo M. Controlled, double-blind study comparing acetylsalicylic acid and diflunisal in the treatment of osteoarthritis of the hip and/or knee; long-term gastroscopic study. In: Miehlke K, ed. Diflunisal in clinical practice. New York: Futura, 1978:63-73.

\title{
Mini-pump: method of diabetic control during minor surgery under general anaesthesia
}

\author{
ANTHONY H BARNETT, MARTIN H ROBINSON, JAMES H HARRISON， PETER J WATKINS
}

\section{Summary and conclusions}

A simple method for maintaining diabetic control during and after minor surgery requiring a general anaesthetic was studied in 20 insulin-treated diabetics. Long-acting insulin was omitted on the night before the operation, and a mini-pump delivering insulin at a rate of $0.5 \mathrm{units} / \mathrm{h}$ was strapped to the arm early on the morning of the operation regardless of the time of operation. Insulin was infused at this rate throughout the day, the usual evening dose of insulin given and followed by supper, and the pump then stopped. In all 20 patients studied blood glucose concentrations fell steadily throughout the day. Hypoglycaemia did not occur.

The mini-pump is simple to use and with the same standard insulin dose for all patients maintains satisfactory blood glucose concentrations throughout the day of operation.

\section{Introduction}

Many regimens for managing insulin-dependent diabetes during surgery have been described. ${ }^{1}$. Unfortunately, blood glucose concentrations tend to fluctuate unpredictably and inadequate control or hypoglycaemia may occur. We have devised a regimen for managing diabetics on the day of operation for those patients undergoing operations requiring a general anaesthetic but no intravenous fluids and after which they may reasonably be expected to be eating and drinking by evening. Our regimen enables the operation to be performed at any time during the day and not necessarily first on the list.

\section{Patients and methods}

We studied 20 insulin-dependent diabetics ( 12 female and 8 male) undergoing surgery. The criteria for selection were that each patient would require a general anaesthetic but no intravenous fluids, and that he would be eating or drinking by the evening of the operation.

Diabetic Department, King's College Hospital, London SE5 9RS

ANTHONY H BARNETT, BSC, MRCP, registrar

MARTIN H ROBINSON, BA, MB, house officer

JAMES H HARRISON, BA, MB, house officer

PETER J WATKINS, MD, FRCP, consultant physician
The operations performed included photocoagulation in seven patients, removal of a lower-segment caesarean section scar, liver biopsy in a child, teeth extraction in two patients, cleaning and debridement of a bed sore, cauterisation of vulval warts, antral washout, various other ENT procedures in four patients, metatarsal osteotomy, and removal of a retinal detachment implant. We also studied a control group of eight insulin-dependent diabetics (five female and three male) undergoing similar types of surgery (three photocoagulation, two teeth extraction, one antral washout, and two orthopaedic drainage procedures).

The patients in both groups were longstanding diabetics (duration of diabetes seven to 50 years). All apart from one in the test group had been receiving insulin from the time of diagnosis of diabetes. Sixteen of the patients in the test group and seven controls had had at least one episode of ketoacidosis during their lives, and in all the diabetes had been diagnosed before the age of 30 years. The mean $( \pm \mathrm{SD})$ daily requirement of insulin in the test group was $48 \cdot 2 \pm 15 \cdot 2$ (range 24-80) units and in the controls 44.5 $\pm 15 \cdot 2$ (range 24-72) units. The mean age of the patients in the test group was 41.8 $\pm 17 \cdot 1$ (range 9-71) years and in the control group 44.1 $\pm 16 \cdot 8$ (range 13-65) years.

The regimen used for the test group is as follows. Only soluble insulin is given on the evening before operation and the mediumacting insulin omitted. The mini-pump is set up first thing in the morning and blood glucose concentrations measured. The minipump is so called because it is light and portable and may be attached by a strap around the arm or by a holster for long periods; it is a miniature version of larger insulin infusion pumps used in acute diabetic emergencies. There are several models: we used the Mill Hill Infuser (fig 1) (Muirhead Ltd, Beckenham, Kent), but a good alternative is the Syringe Driver type MS16 (Pye Dynamics). Both pumps are battery operated and drive a syringe in which soluble insulin is diluted in physiological saline with no additives. The pump is connected to a peripheral arm vein by means of a "butterfly" indwelling needle. Insulin is infused at a standard rate of 0.5 units/h throughout the day of operation. The operation may conveniently be performed at any time during the day. Feeding is resumed that

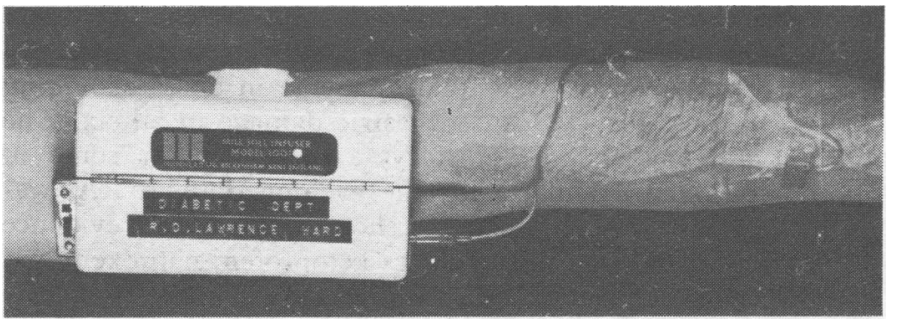

FIG 1-Mini-pump attached to arm and connected to peripheral vein by "butterfly" indwelling needle. 
evening, the appropriate evening dose of insulin given, and the pump discontinued. For the purpose of this trial two-hourly blood glucose measurements were performed throughout the day and immediately before supper.

In the control group of patients the same procedure was carried out but the mini-pump was not used. No insulin was given on the day of the operation unless the blood glucose concentration increased to more than $20 \mathrm{mmol} / 1(360 \mathrm{mg} / 100 \mathrm{ml})$, when it was given subcutaneously.

\section{Results}

In all the patients in whom the mini-pump was used blood glucose concentrations decreased steadily throughout the day (fig 2). The mean $( \pm S D)$ preoperative concentration was $14.6 \pm 4.3 \mathrm{mmol} / 1$ $(263 \pm 77 \mathrm{mg} / 100 \mathrm{ml}$ ) (range $6.8-22.0 \mathrm{mmol} / 1 ; 122-396 \mathrm{mg} / 100 \mathrm{ml}$ ). The mean concentration before supper was $8 \cdot 7 \pm 2.9 \mathrm{mmol} / 1(157 \pm 52$ $\mathrm{mg} / 100 \mathrm{ml}$ ) (range 3.2-12 mmol/1; 58-216 mg/100 ml). Hypoglycaemia did not occur.

In all eight controls blood glucose concentrations increased throughout the day of operation. The mean preoperative concentration was $14 \cdot 2 \pm 2.5 \mathrm{mmol} / 1(256 \pm 45 \mathrm{mg} / 100 \mathrm{ml})$ (range $12-18 \mathrm{mmol} / 1$; 216$324 \mathrm{mg} / 100 \mathrm{ml}$ ). The mean concentration before supper was $16 \cdot 4+2.9$ $\mathrm{mmol} / \mathrm{l}(295 \pm 52 \mathrm{mg} / 100 \mathrm{ml})$, but by this time three patients had been

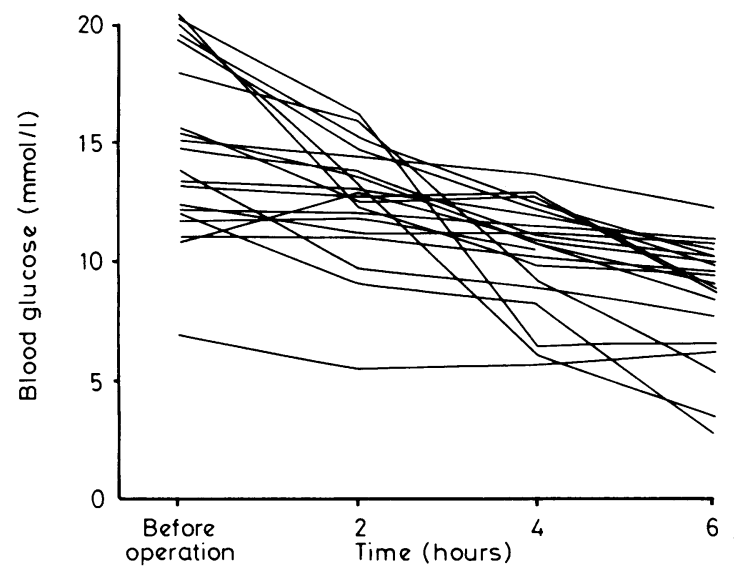

FIG 2-Individual plasma glucose concentrations on day of surgery in diabetic patients under mini-pump control. Concentrations were measured before and then two, four, and six hours after operation.

Conversion: SI to traditional units-Blood glucose: $1 \mathrm{mmol} / 1 \approx 18 \mathrm{mg} / 100 \mathrm{ml}$.

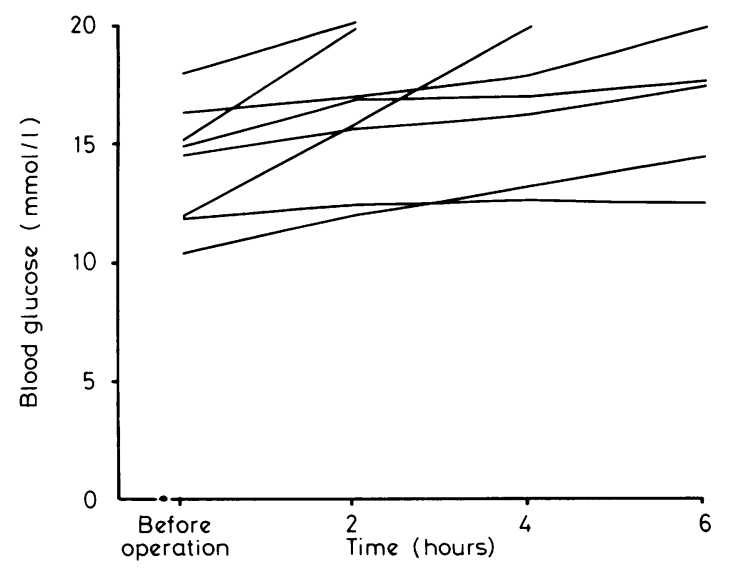

FIG 3-Individual plasma glucose concentrations on day of surgery in diabetic patients who received no insulin on that day (concentrations measured before and two, four, and six hours after operation).

Conversion: SI to traditional units-Blood glucose: $1 \mathrm{mmol} / 1 \approx 18 \mathrm{mg} / 100 \mathrm{ml}$ eliminated from the study as their concentrations had increased to over $20 \mathrm{mmol} / 1(360 \mathrm{mg} / 100 \mathrm{ml})$ (fig 3). These patients were then given insulin supplements. In one patient the diabetes became severely uncontrolled, with a blood glucose concentration of 20 $\mathrm{mmol} / \mathrm{l}$ and a serum bicarbonate of $14 \mathrm{mmol} / 1(\mathrm{mEq}) / 1$.

\section{Discussion}

Continuous intravenous infusion was first introduced to manage ketoacidosis ${ }^{2}$ and is now also used in other diabetic emergencies and after major surgery, ${ }^{3}{ }^{4}$ for which it remains a valuable technique. We have shown that the mini-pump maintains acceptable blood glucose concentrations throughout the day in diabetics undergoing more-minor forms of surgery. It eliminates the anxiety surrounding the gross variations in blood glucose concentration when traditional regimens are used and permits a steady fall from the preoperative concentration throughout the day. (In contrast, when no insulin is given the blood glucose concentration usually increases steadily ${ }^{1}$ (fig 3) and the danger of ketoacidosis is always present.) Thus the operation may be performed at any time during the day and not necessarily first on the list and a standard regimen identical for all patients may be used. Two-hourly measurements of blood glucose will not usually have to be performed: this was only done for the purposes of this study, and one or two measurements will usually suffice.

Hypoglycaemia did not occur in any patient when the insulin infusion rate was 0.5 units per hour. During pilot studies when one unit per hour was used patients tended to become hypoglycaemic before the evening meal.

Thus the mini-pump is simple to use and successfully maintains adequate blood glucose concentrations in diabetics undergoing minor surgery and requiring a general anaesthetic.

We should like to thank Dr D A Pyke for his help in producing this paper.

Requests for reprints should be sent to AHB.

\section{References}

1 Alberti KGMM, Thomas DJB. The management of diabetes during surgery. $\mathrm{Br} \mathcal{F}$ Anaesth 1979;51:693-710.

2 Page MMcB, Alberti KGMM, Greenwood R, et al. Treatment of diabetic coma with continuous low-dose infusion of insulin. Br Med $\mathcal{F} 1974$;2: 687-90.

${ }^{3}$ Leslie RDG, Mackay JD. Intravenous insulin infusion in diabetic emergencies. $\mathrm{Br}$ Med $\mathcal{F}$ 1978;2:1343-4.

4 Taitelman U, Reece EA, Bessman AN. Insulin in the management of the diabetic surgical patient. $\mathcal{F} A M A 1977 ; 237: 658-60$.

(Accepted 11 October 1979)

ONE HUNDRED YEARS AGO SIR,-Perhaps some of your readers would kindly assist me in the following case. My patient is a young (unmarried) lady aged 26, fair, slight, and of nervous temperament. She enjoyed good health till three years ago, when she had rheumatic fever (subacute). For some months after this, she had pains occasionally in her wrists and ankles. Eighteen months ago, ovarian irritation and menorrhagia commenced, and lasted for eight or nine months. Nine months ago-i.e., just after the ovarian irritation seemed to have been overcome-her present distress commenced; and it is for what follows I wish advice. On being exposed to even a light draught of cold air, as in going from the parlour to the drawing-room, her hands become quite cold and bloodless: they are first pale, then livid and painful, and as cold as snow. Circulation seems to be quite stopped for the time, and her hands look like those of a corpse. She has become very irritable and peevish, and is very hard to live with. I have tried nux vomica, arsenic, cod-liver oil, Euston's syrup, valerian (different preparations), bromides, iodides, cold sponging, flesh-brushes, electro-magnetism, and out-door exercise, all to no purpose. I would also like to hear of a Continental watering-place or spa (cheap), suitable for such a case. The whole family would like to go from May till September.-Yours truly, M.B. (British Medical fournal, 1880.) 